\title{
KREDIBILITET RECENZIJA KVALITETA USLUGE BEOGRADSKIH HOTELA NA PORTALU TRIPADVISOR
}

\author{
Saša Mašić ${ }^{1}$, Nikolina Kosar ${ }^{1}$, Lazar Kalmić \\ ${ }^{1}$ Visoka hotelijerska škola, Beograd \\ ${ }^{2}$ Geografski fakultet, Beograd
}

\begin{abstract}
:
Tripadvisor pripada grupi eWOM (electronic word of mouth- eWOM - elektronska komunikacija "od usta do usta") portala i prema rezultatima brojnih istraživanja jedan je od najuticajnijih portala tog tipa kada je u pitanju hotelsko poslovanje. Na njemu korisnici razmenjuju informacije u vezi kvaliteta hotelskih usluga. Na Tripadvisor-u je predstavljeno više od 748.000 hotela i registruje se oko 260 miliona poseta na mesečnom nivou. U stručnoj literaturi se često kao zamerka navodi činjenica da se prilikom postavljanja komentara na portal ne traži nikakav dokaz da je osoba koja ocenjuje kvalitet usluge uopšte bila gost tog hotela, što ostavlja prostor za sumnju u verodostojnost postavljenih recenzija. Cilj ovog rada je da se oceni kredibilitet recenzija beogradskih hotela na Tripadvisor-u. Kredibilitet recenzija je ocenjen na dva načina. Upoređena je prosečna ocena kvaliteta usluge beogradskih hotela na Tripadvisor-u sa prosečnom ocenom utvrđenom na osnovu recenzija predstavljenih na on-line rezervacionim sistemima Booking.com, Hotels.com, Expedia.com, Venere.com, HRS.com i Orbitz.com, a na kojima je pre postavljanja komentara prethodno potrebno dokazati boravak u tom hotelu izvršenom rezervacijom ili čak i potvrdom od strane samog hotela da je gost u njemu i boravio. Takođe, komparirane su prosečne ocene beogradskih hotela na Tripadvisor-u, a u okviru različitih kategorija. Dobijeni rezultati jasno ukazuju da ne postoji značajnije odstupanje između ocena kvaliteta hotelske usluge na Tripadvisor-u i svakog od pojedinačnih on-line rezervacionih sistema. Uočeno je da je, komparativno posmatrano, ocena kvaliteta hotelske usluge analiziranih hotela na Tripadvisor-u u proseku nešto niža u odnosu na prosek utvrđen za svaki od analiziranih on-line rezervacionih portala. S druge strane dobijeni rezultat ukazuje da su ocene korisnika na Tripadvisor-u usklađene sa formalnim kategorijama hotela i da na nivou proseka nisu registrovana odstupanja koja bi ukazala na to da su hoteli nižih kategorija bolje ocenjeni od onih koji pripadaju višim kategorijama.
\end{abstract}

\author{
Key words: \\ Tripadvisor, \\ Rezervacioni sistemi, \\ Kredibilitet, \\ Hoteli, \\ Beograd.
}

\section{UVOD}

Danas se na Internetu može pronaći veliki broj portala koji se u literaturi nazivaju eWOM (electronic word of mouth-eWOM) portali [1],[3],[4],[6],[8]. Postoji mnoštvo takvih portala specijalizovanih za razmenu informacija o kvalitetu hotelskih usluga. Oni nude obilje informacija o hotelima koje su postavili potrošači koji su prethodno koristili njihove usluge. Upravo te ocene omogućavaju korisnicima kreiranje određenog posrednog iskustva, na osnovu kojeg oni formiraju svoja očekivanja u vezi kvaliteta hotelske usluge [10].

Neki od eWOM portala su se razvili upravo na ideji razvijanja web platforme putem koje bi zainteresovani korisnici mogli razmenjivati informacije o kvalitetu usluge pojedinih hotela, restorana, turističkih destinacija. Najpoznatiji predstavnik ovakvih portala je svakako Tripad- on-line rezervacionih sistema koji korisnike svojih usluga podstiču da po iskorišćenoj hotelskoj usluzi na web portalu rezervacionog sistema napišu ocenu njenog kvaliteta. Ta recenzija je dalje dostupna svim posetiocima web portala ovih on-line rezervacionih sistema. Među najpoznatijim takvim on-line rezervacionim sistemima su booking.com, expedia.com, hotels.com itd. Na tržištu je zabeležen i veliki broj slučajeva povezivanja klasičnih on-line posrednika sa portalom Tripadvisor u smislu da su na portalima on-line rezervacionih sistema postavljenje ocene sa Tripadvisor-a. Kao takav primer se može navesti saradnja on-line rezervacionog sistema travelocity.com i portala tripadvisor.com.

Brz razvoj Interneta, širenje njegove dostupnosti, integracija sa mobilnom telefonijom su doveli do značajnih promena u ponašanju potrošača prilikom kupovine hotelskog proizvoda. Pored tradicionalnih faktora kao što su lokacija, brend, sadržaji, cena usluge, programi lojalnosti, na izbor hotela utiču i ocene i komentari korisnika njihovih 
usluga, dostupni na Internet-u. Svi ovi faktori zajedno čine jedan miks koji utiče na izbor hotela od strane potrošača [13]. Danas sve veći broj ljudi prilikom rezervacije hotelske usluge izbegava tradicionalne posrednike već se informiše i kupuje usluge on-line koristeći kako personalne računare tako i „smart” mobilne telefone.

Tripadvisor na svom portal navodi rezulutat istraživanja iz marta 2013. godine prema kojem 32\% putnika iz SAD rezerviše uslugu smeštaja preko web portala samih hotela, dok $28 \%$ njih to čini preko on-line posrednika. Pojedina istraživanja ukazuju na to da je izbor hotela u čak $88 \%$ slučajeva pod snažnim uticajem sadržaja kojima su ti hoteli predstavljeni na eWOM portalima [12]. To implicira da je ukupan obim prodaje hotelske usluge smeštaja, a samim tim i poslovni rezultat hotela, pod uticajem sadržaja on-line recenzija. Istraživanja sprovedena u Srbiji, na uzorku beogradskih hotela, pokazuju da postoji visok stepen korelacije između on-line imidža hotela i poslovnih performasi hotela iskazanih kroz pokazatelj TREVPAR (Total Revenue Per Available Room - kalkuliše se tako što se ukupni poslovni prihodi stave u odnos sa ukupnim raspoloživim smeštajnim kapacitetom hotela na godišnjem nivou). Rezultati ukazuju da je to naročito slučaj kod beogradskih hotela druge i treće kategorije [2].

Prema podacima sa samog sajta Tripadvisor može se zaključiti da se radi o vrlo uticajnom eWOM portalu. Tripadvisor na mesečnom nivou ima ukupno oko 260 miliona poseta. Na njemu je predstavljeno više od 748.000 hotela, a svakog minuta se napiše u proseku oko 80 novih recenzija. Jasno je da je e-WOM uticajniji u odnosu na klasičnu promociju „od usta do usta“ jer omogućava brži prenos informacija do neuporedivo većeg broja korisnika bez potrebe za kontaktom „lice u lice“ [11]. Prilagođavajući se konstantnom i brzom tehnološkom napretku koji izaziva promene u ponašanju potrošača Tripadvisor je razvio i aplikaciju za „smart" telefone putem koje je moguće pristupiti svim sadržajima. Tu aplikaciju je do sada preuzelo oko 69 miliona korisnika. Od ukupnog broja poseta oko $10-15 \%$ je registrovano upravo sa mobilnih platformi („smart" telefoni i tablet računari $)^{1}$.

Da bi napisali ocenu kvaliteta usluge korisnici portala Tripadvisor se moraju registrovati. Ipak, prilikom ostavljanja komentara ne traži se nikakav dokaz da je osoba koja ocenjuje kvalitet usluge uopšte bila gost tog hotela, što ostavlja prostor za sumnju u verodostojnost postavljenih recenzija. Može se postaviti i pitanje da li zaposleni u hotelu sami pišu izrazito pozitivne komentare o svojim objektima? U isto vreme ništa, osim poslovnog morala, ne sprečava hotelijere da napišu i negativan komentar o konkurentskom hotelu. Navode se i slučajevi da su u pojedinim situacijama hotelijeri ponudili novac pojedincima da uklone svoje komentare sa ovakvih portala [9].

On-line rezervacioni portal obično imaju sasvim drugačiji pristup. Najčešće se kao uslov za pisanje ocene kvaliteta usluge pojedinog hotela postavlja prethodno izvršena rezervacija hotela preko tog on-line posrednika. Pojedini portali idu čak i dalje i traže od hotela potvrdu da je gost zaista boravio u hotelu i tek onda omogućavaju postavljanje komentara.

\footnotetext{
1 www.tripadvisor.com, pristup 11.02.2014.
}

Imajući u vidu nesumnjiv značaj Tripadvisor-a cilj ovog rada je da se utvrdi kredibilitet ocene kvaliteta beogradskih hotela na portalu Tripadvisor. Kredibilitet recenzija je ocenjen na dva načina:

- Poređenjem prosečne ocene beogradskih hotela na Tripadvisor-u, a okviru različitih formalnih kategorija;

- Komparacijom recenzija kvaliteta usluge beogradskih hotela na Tripadvisor-u sa recenzijama ostavljenim na nekim od najvećih on-line rezervacionih sistema. Činjenica je da na Tripadvisor-u pojedinci mogu, želeći da poprave reputaciju svog hotela i/ili naruše reputaciju konkurentskog, ostaviti ocene kvaliteta hotelske usluge, a da prethodno ne dokažu da su bili gosti u tim hotelima. Ako je to zaista masovna praksa, za očekivati je da će se pojaviti značajna razlika u recenzijama beogradskih hotela na Tripadvisor-u i onim ostavljenim na online rezervacionim sistemima gde je pre ostavljanja komentara prethodno potrebno dokazati boravak u tom hotelu izvršenom rezervacijom ili čak i potvrdom od strane hotela da je gost u njemu boravio.

\section{METODOLOGIJA ISTRAŽIVANJA}

Na osnovu spiska kategorisanih hotela objavljenih na portalu Ministarstva privrede - Sektora za turizam, za svaki pojedinačni beogradski hotel izvršen je uvid na portalu Tripadvisor i utvrđen je numerički prosek ocena koje su ostavili korisnici. Prosek je utvrđen kao ponderisana sredina, a za utvrđivanje pondera je korišćen broj ostavljenih komentara.

$\mathrm{Za}$ iste hotele je i na on-line rezervacionim portalima Booking.com, Hotels.com, Expedia.com, Venere. com, HRS.com i Orbitz.com utvrđena prosečna ocena na osnovu komentara koje su dali korisnici koji su prethodno preko njih izvršili rezervaciju. Sistem ocenjivanja, odnosno primenjena skala se razlikovala od portala do portala. Tako se na Tripadvisor-u, Hotels.com, Expedia.com i Orbitz.com kvalitet usluge hotela može oceniti ocenom od 1 do 5, dok se na Booking.com, Venere.com i HRS.com ocenjuju ocenom do 10. Kako bi se obezbedila jednobraznost i mogućnost upoređivanja sve ocene su preračunate na skalu od 0 do 1 . Prosečna ocena je utvrđena kao ponderisana sredina, a za utvrđivanje pondera je korišćen broj komentara.

Utvrđene su i prosečne vrednosti ocena na Tripadvisor-u u okviru beogradskih hotela iste kategorije kako bi se utvrdilo da li hoteli, formalno više kategorije, imaju u proseku i višu prosečnu vrednost ocena na portalu Tripadvisor.

$\mathrm{Na}$ osnovu prikupljenih i statistički obrađenih podataka upoređeni su proseci ocena beogradskih hotela na portalu Tripadvisor sa prosecima iz Booking.com, Hotels. com, Expedia.com, Venere.com, HRS.com i Orbitz.com kako bi se utvrdilo da li se može registrovati njihovo značajnije međusobno odstupanje.

Istraživanje je sprovedeno tokom januara 2014. godine. 


\section{ANALIZA REZULTATA}

Rezultati istraživanja pokazuju da su na portalu Tripadvisor predstavljena 53 kategorisana beogradska hotela sa ukupno 3.962 recenzije. Na osnovu njih je utvrđena prosečna ocena kvaliteta usluge ovih hotela koja je iznosila 3,99 na petostepenoj skali. Registrovan prosek je nešto viši od onog koji je utvrđen na kraju 2012. godine na nivou svih hotela iz Srbije i koji je iznosio 3,92 [2].

Ako se pođe od pretpostavke da su kriterijumi za kategorizaciju hotela u Srbiji dobro postavljeni kao i da je proces kategorizacije kvalitetno sproveden, jedan od načina za vrednovanje kredibiliteta ocena na Tripadvisor-u bi moglo biti poređenje utvrđenih proseka u okviru pojedinih kategorija hotela. Za očekivati je da bi na uzorku hotela viših kategorija trebali registrovati i višu prosečnu ocenu na Tripadvisor-u.

Iz rezultata predstavljenih u Tabeli 1 se uočava da se kod hotela viših kategorija registruje i viša prosečna ocena utvrđena na osnovu recenzija na Tripadvisor-u.

TABELA 1 PROSEČNA OCENA KOMENTARA NA PORTALU TRIPADVISOR U OKVIRU RAZLIČITIH HOTELSKIH KATEGORIJA

\begin{tabular}{lccc}
\hline Kategorija & $\begin{array}{c}\text { Prosečna } \\
\text { ocena }\end{array}$ & $\begin{array}{c}\text { Broj ko- } \\
\text { mentara }\end{array}$ & $\begin{array}{c}\text { Prosečan } \\
\text { broj } \\
\text { komentara } \\
\text { po hotelu }\end{array}$ \\
\hline Prva kategorija $\left(5^{*}\right)$ & 4,50 & 434 & 145 \\
Druga kategorija $\left(4^{*}\right)$ & 4,10 & 2.274 & 95 \\
Treća kategorija (3*) & 3,84 & 1.026 & 57 \\
Četvrta kategorija $\left(2^{*}\right)$ & 2,54 & 228 & 29
\end{tabular}

Izvor: Sopstveno istraživanje

Takođe, prosečan broj recenzija po hotelu je značajno veći kod hotela viših kategorija. Dobijen rezultat ukazuje da su ocene korisnika u proseku usklađene sa formalnim kategorijama hotela i da na nivou proseka nisu registrovana odstupanja koja bi ukazala na to da su hoteli nižih kategorija bolje ocenjeni od onih koji pripadaju višim kategorijama.

$\mathrm{Na}$ web-u postoji veliki broj portala koji pružaju mogućnost rezervacije hotelske usluge. $\mathrm{Na}$ takvim portalima je često prisutan i veliki broj ocena kvaliteta usluge različitih hotela koje su napisali korisnici njihovih usluga. Da bi korisnik bio u prilici da napiše recenziju osnovni uslov je da je preko tog portala u prethodnom periodu izvršio rezervaciju hotelske usluge. Pojedini portali zahtevaju čak i potvrdu od strane hotela da je gost u hotelu zaista boravio, a pre nego što se on pozove da oceni kvalitet usluge hotela. Ovakav sistem otežava mogućnost da recenzije hotela napišu i osobe koje uopšte nisu bili korisnici njihovih usluga. Kredibilitet recenzija sa Tripadvisor-a može biti ocenjen i poređenjem sa recenzijama postavljenim na nekim od ovakvih rezervacionih portala.

Za potrebe ovog rada izvršena je komparacija prosečne ocene beogradskih hotela sa portala Tripadvisor i portala Booking.com, Hotels.com, Expedia.com, Venere.com, HRS.com i Orbitz.com.
Pre nego što je izvršeno bilo kakvo poređenje bilo je potrebno prilagoditi uzorke. Naime, poređenje ima smisla jedino ako se upoređuju recenzije istih hotela na različitim portalima. U praksi nisu svi hoteli ocenjeni na Tripadvisor-u prisutni na navedenim rezervacionim portalima pa su u analizu uključeni samo oni hoteli koji su prisutni kako na portalu Tripadvisor tako i na portalu sa čijim ocenama se vrši komparacija. To znači da se uzorak hotela menja u slučaju komparacije ocena sa Tripadvisor-a i svakog od pojedinačnih rezervacionih portala.

\section{Komparacija Tripadvisor.com -Booking.com}

Booking.com je komisioni rezervacioni portal [5], deo kompanije Priceline.com (Nasdaq: PCLN) i predstavlja svetskog lidera u on-line rezervacijama smeštaja. Kompanija je osnovana 1996. godine. Danas je Booking.com dostupan na više od 40 jezika i u svojoj ponudi ima preko 425.418 objekata za smeštaj u 195 zemalja. Preko ovog portala se na nedeljnom nivou izvrši rezervacija oko 2,8 miliona noćenja. Booking.com ima sedište u Amsterdamu u Holandiji, i internacionalno je podržan od strane 115 kancelarija u preko 50 zemalja širom sveta ${ }^{2}$.

Misija ove kompanije je da pomogne turistima i poslovnim putnicima, bez obzira na njihove budžete, da lako otkriju, rezervišu i uživaju u najboljim svetskim hotelima i smeštajnim objektima.

Istraživanjem je utvrđeno da za 51 beogradski hotel postoje komentari i ocene kako na portalu Tripadvisor tako i na Booking.com i oni su činili analizirani uzorak. Rezultati poređenja su predstavljeni u Tabeli 2.

TABELA 2 PROSEČNA OCENA KOMENTARA NA TRIPADVISOR-U I BOOKING.COM NA UZORKU BEOGRADSKIH HOTELA

\begin{tabular}{lcc}
\hline WEB PORTAL & $\begin{array}{c}\text { PROSEČNA } \\
\text { OCENA }\end{array}$ & $\begin{array}{c}\text { BROJ RECEN- } \\
\text { ZIJA }\end{array}$ \\
\hline Tripadvisor.com & 0,80 & 3.948 \\
Booking.com & 0,83 & 9.925 \\
\hline
\end{tabular}

Izvor: Sopstveno istraživanje

Rezultati istraživanja ukazuju da je prosečna ocena hotela na oba portala vrlo slična. Ipak, treba konstatovati da je registrovana viša vrednost proseka u slučaju portala booking.com.

\section{Komparacija Tripadvisor.com -Hotels.com}

Hotels.com je rezervacioni portal putem kojeg je moguće izvršiti rezervaciju usluga „online” i putem telefona. Sedište kompanije nalazi se u Dalasu, Teksas, SAD. Kompanija ima 85 sajtova na 34 jezika, a u svojoj ponudi ima preko 240.000 hotela na približno 19.000 lokacija $^{3}$. Spada

2 http://www.booking.com/index.sr.html, pristup 11.02.2014.

3 http://www.hotels.com/customer_care/about_us.html, pristup 11.02.2014. 
u grupu prodajnih web sajtova - merchant website [5].

Kako bi se moglo izvršiti poređenje između ocena na ovom rezervacionom portalu i Tripadvisor-u identifikovana su 33 beogradska hotela ocenjena istovremeno na oba portala.

TABELA 3 PROSEČNA OCENA KOMENTARA NA TRIPADVISORU I HOTELS.COM NA UZORKU BEOGRADSKIH HOTELA

\begin{tabular}{lcc}
\hline WEB PORTAL & $\begin{array}{c}\text { PROSEČNA } \\
\text { OCENA }\end{array}$ & $\begin{array}{c}\text { BROJ RECEN- } \\
\text { ZIJA }\end{array}$ \\
\hline Tripadvisor.com & 0,82 & 2.856 \\
Hotels.com & 0,83 & 1.222 \\
\hline
\end{tabular}

Izvor: Sopstveno istraživanje

Iz prezentovanih podataka u Tabeli 3 se može uočiti izrazito slična vrednost prosečne ocene kvaliteta analiziranih beogradskih hotela na oba web portala. Registruje se nešto niža prosečna vrednost ocena na portalu Tripadvisor u odnosu na hotels.com.

\section{Komparacija Tripadvisor.com -Expedia.com}

Prema podacima sa portala Expedia može se zaključiti da je na njemu predstavljena ponuda preko 240.000 hotela širom sveta. Pored hotela na ovom portalu se može izvršiti i kupovina turističkih paket aranžmana, avionskih karata, krstarenja, rent-a-car usluge itd. Kategoriše se u grupu prodajnih web sajtova [5].

Identifikovan je 31 beogradski hotel čija je usluga ponuđena na portalu Expedia.com, a da je istovremeno prisutan i ocenjen i na Tripadvisor-u. Rezultati poređenja prosečnih ocena su predstavljeni u Tabeli 4.

TABELA 4 PROSEČNA OCENA KOMENTARA NA TRIPADVISOR-U I EXPEDIA.COM NA UZORKU BEOGRADSKIH HOTELA

\begin{tabular}{lcc}
\hline WEB PORTAL & $\begin{array}{c}\text { PROSEČNA } \\
\text { OCENA }\end{array}$ & $\begin{array}{c}\text { BROJ RECEN- } \\
\text { ZIJA }\end{array}$ \\
\hline Tripadvisor.com & 0,80 & 2.867 \\
Expedia.com & 0,85 & 538 \\
\hline
\end{tabular}

Izvor: Sopstveno istraživanje

Može se konstatovati da ne postoji značajnija razlika između prosečne ocene kvaliteta usluge beogradskih hotela na portalima Tripadvisor i Expedia. Kao i u prethodnim slučajevima prosečna ocena na Tripadvisor-u je nešto niža u odnosu na rezervacioni portal s kojim se upoređuje.

\section{Komparacija \\ Tripadvisor.com -HRS.com}

HRS.com je portal koji agregira ponudu oko 250.000 hotela širom sveta ${ }^{4}$. Spada u grupu komisionih web sajtova [5].

4 http://www.hrs.com, pristup 11.02.2014.
Na HRS.com je prisutna ponuda 24 beogradska hotela koji su istovremeno ocenjeni i na portalu Tripadvisor i oni čine uzorak na osnovu kojeg se vrši poređenje.

TABELA 5 PROSEČNA OCENA KOMENTARA NA TRIPADVISOR-U I HRS.COM NA UZORKU BEOGRADSKIH HOTELA

\begin{tabular}{ccc}
\hline WEB PORTAL & $\begin{array}{c}\text { PROSEČNA } \\
\text { OCENA }\end{array}$ & $\begin{array}{c}\text { BROJ RECEN- } \\
\text { ZIJA }\end{array}$ \\
\hline Tripadvisor.com & 0,82 & 2.097 \\
HRS.com & 0,84 & 201 \\
\hline Izvor: Sopstveno istraživanje &
\end{tabular}

Kao što se može uočiti iz podataka iz Tabele 5 registruje se tek marginalna razlika u utvrđenoj prosečnoj vrednosti ocene kvaliteta beogradskih hotela na posmatranim portalima. Prosečna ocena na Tripadvisor-u je i u ovom slučaju nešto malo niža u odnosu na rezervacioni portal s kojim se upoređuje, u ovom slučaju na prosečnu vrednost sa HRS.com

\section{Komparacija Tripadvisor.com -Venere.com}

Osnovana 1995.godine, Venere Net predstavlja izuzetan slučaj u kojem italijanska kompanija postiže uspeh na međunarodnom nivou u e - poslovnom svetu, gde tradicionalno dominiraju američke i druge strane kompanije.

Rezervacioni portal Venere.com spada u grupu komisionih web sajtova [5] i obezbeđuje ponudu preko 135.000 hotela širom sveta.

Tokom istraživanja identifikovana je ponuda 20 beogradskih hotela na ovom sajtu, a koji su istovremeno ispunjavali uslov da su predstavljeni i na Tripadvisor-u.

Utvrđena vrednost prosečnih ocena kvaliteta beogradskih hotela je predstavljena u Tabeli 6 .

TABELA 6 PROSEČNA OCENA KOMENTARA NA TRIPADVISOR-U I VENERE.COM NA UZORKU BEOGRADSKIH HOTELA

\begin{tabular}{lcc}
\hline WEB PORTAL & $\begin{array}{c}\text { PROSEČNA } \\
\text { OCENA }\end{array}$ & $\begin{array}{c}\text { BROJ RECEN- } \\
\text { ZIJA }\end{array}$ \\
\hline Tripadvisor.com & 0,80 & 1.868 \\
Venere.com & 0,83 & 136 \\
\hline
\end{tabular}

Izvor: Sopstveno istraživanje

Kao što se može zaključiti iz predstavljenih rezultata, ne registruje se značajnije odstupanje u utvrđenim prosečnim vrednostima ocena kvaliteta hotelske usluge beogradskih hotela između portala Tripadvisor i Venere.com.

\section{Komparacija \\ Tripadvisor.com -Orbitz.com}

Komisioni web portal Orbitz.com [5] nudi kako usluge hotelskog smeštaja, tako i avio karte, paket aranžmane, krstarenja, rent-a-car usluge itd. 
Na portalu je prisutna ponuda 14 beogradskih hotela istovremeno predstavljenih i na portalu Tripadvisor.

TABELA 7 PROSEČNA OCENA KOMENTARA NA TRIPADVISORU I ORBITZ.COM NA UZORKU BEOGRADSKIH HOTELA

\begin{tabular}{lcc}
\hline Web portal & $\begin{array}{c}\text { Prosečna } \\
\text { ocena }\end{array}$ & $\begin{array}{c}\text { Broj } \\
\text { recenzija }\end{array}$ \\
\hline Tripadvisor.com & 0,80 & 1.805 \\
Orbitz.com & 0,84 & 47 \\
\hline
\end{tabular}

Izvor: Sopstveno istraživanje

Baš kao i u slučaju svih prethodnih komparacija ocena, ne uočava se bitno odstupanje utvrđenih proseka. Ono što je značajno naglasiti je da je prosek ocena kvaliteta beogradskih hotela na Tripadvisor-u opet, kao i u svim prethodnim slučajevima, bio niži od proseka utvrđenog na osnovu recenzija sa rezervacionog portala.

\section{ZAKLJUČAK}

Da bi ostavili komentar i ocenili kvalitet usluge na portalu Tripadvisor nije potrebno da prethodno dokažete da ste bili gost tog hotela. Ova činjenica otvara prostor za sumnju u kredibilitet ocena kvaliteta hotelske usluge koje se mogu pronaći na ovom portalu. Iz tog razloga značajno je utvrditi da li se prosečna ocena kvaliteta usluge beogradskih hotela na portalu Tripadvisor značajno razlikuje od takvih ocena na on-line rezervacionim portalima na kojima je pre ocenjivanja kvaliteta usluge prethodno potrebno dokazati korišćenje hotelske usluge, bar izvršenom rezervacijom.

Rezultati istraživanja sprovedenog za potrebe ovog rada ukazuju da na uzorku beogradskih hotela ne postoje značajne razlike između ocena kvaliteta njihovih usluga na portalu Tripadvisor i on-line rezervacionim portalima Booking.com, Hotels.com, Expedia.com, Venere.com, HRS.com i Orbitz.com. Utvrđene prosečne vrednosti su uvek bile vrlo slične, s tim da je prosek ocena na portalu Tripadvisor u svakom od pojedinačnih poređenja bio čak i nešto niži u odnosu na proseke sa on-line rezervacionih portala.

Moguće je da pojedini hotelijeri koriste šansu da na Tripadvisor-u napišu afirmativne ocene kvaliteta sopstvene usluge kako bi popravili vlastiti on-line imidž. Ipak, ako je to masovna i česta praksa bilo bi za očekivati da je prosečna ocena na Tripadvisor-u značajno viša u odnosu na prosečnu ocenu na on-line rezervacionim portalima. Dobijeni rezultati ne potvrđuju takvu tendenciju. Naprotiv, registrovana prosečna vrednost ocena na Tripadvisor$\mathrm{u}$ je u svakom pojedinačnom poređenju bila malo niža u odnosu na prosek ocena sa analiziranih on-line rezervacionih sistema.

Važno je naglasiti da ni pojedini on-line rezervacioni sistemi nisu imuni na mogućnost postavljanja neobjektivnih komentara koje bi mogli napisati i sami hotelijeri u cilju unapređenja on-line reputacije. Jedina razlika u odnosu na postavljanje takvih komentara na Tripadvisor-u je što ne bi bili besplatni već bi bili povezani sa troškovima posredničke provizije.
U isto vreme, utvrđene prosečne vrednosti ocena beogradskih hotela na portalu Tripadvisor, a u okviru različitih kategorija, u potpunosti odgovaraju očekivanjima. Naime, hoteli viših kategorija u proseku imaju i bolje ocene na portalu Tripadvisor.

Pod uslovom da je sistem kategorizacije hotela u Srbiji kvalitetno postavljen, kao i da se Pravilnik o standardima za kategorizaciju ugostiteljskih objekata za smeštaj pravilno i potpuno implementira u praksi, rezultati ukazuju da ocene na Tripadvisor-u adekvatno oslikavaju kvalitet usluga beogradskih hotela.

\section{LITERATURA}

[1] Bronner, F., De Hoog, R. (2010) „Consumer-generated versus marketer generated websites in consumer decision making", International Journal of Market Research, Vol. 52 , No.2, pp. 231-248.

[2] Čačić, K., Mašić, S. (2013) „Uticaj portala Tripadvisor na poslovanje hotela u Srbiji”, Marketing, Vol 44, No. 3, str. 211-220.

[3] Goldsmith, R. Horowitz, D. (2006) „Measuring motivations for online opinion seeking", Journal of Interactive Advertising, Vol. 6, No. 2, pp. 1-16.

[4] Hennig-Thurau, T., Walsh, G. (2003) „Electronic Wordof-Mouth: Motives for and Consequences of Reading Customer Articulations on the Internet", International Journal of Electronic Commerce, Vol. 8, No. 2, pp. 51-74.

[5] Kosar, Lj., Svorcan, N. (2008) „Poslovanje recepcije i hotelskog domaćinstva", Visoka hotelijerska škola, Beograd

[6] Litvin, S., Goldsmith, R., Pan, B. (2008) „Electronic wordof-mouth in hospitality and tourism management", Tourism Management, Vol. 29, No. 3, pp. 458-468

[7] Pravilnik o standardima za kategorizaciju ugostiteljskih objekata za smeštaj, Službeni glasnik Republike Srbije, 41/2010, Beograd

[8] Purnawirawan, N., De Pelsmacker, P., Dens, N. (2012) „Balance and Sequence in Online Reviews: How Perceived Usefulness Affects Attitudes and Intentions", Journal of interactive marketing, Vol. 26, No. 4, pp. 244-255.

[9] Sharkey, G. (2009) „True or false? You decide”, Caterer \& Hotelkeeper, Vol. 199, No. 4591, pp. 30-32.

[10] Sparks, B., Browning, V. (2011) „The impact of online reviews on hotel booking intentions and perception of trust", Tourism Management, Vol 32, pp. 1310-1323.

[11] Sun, T., Youn, S., Wu, G., Kuntaraporn, M. (2006) „Online word-of-mouth: an explo-ration of its antecedents and consequences", Journal of Computer-Mediated Communication 11, pp. 1104-1127.

[12] Tuominen P. (2010) The Influence of TripAdvisor Consumer-Generated Travel Reviews on Hotel Performance, http://uhra.herts.ac.uk/bitstream/handle/2299/7612/S128. pdf?sequence=1, pristupljeno 27.03.2013.god.

[13] Verma, R. (2010) „Customer choice modeling in hospitality services: a review of past research and discussion of some new applications", Cornell Hospitality Quarterly, Vol. 51, No.4, pp. 470-478. 


\section{CREDIBILITY OF BELGRADE HOTEL SERVICE QUALITY REVIEWS ON TRIPADVISOR}

\begin{abstract}
:
Tripadvisor is eWOM (electronic word of mouth) portal and according to the results of numerous studies it is one of the most influential portals when it comes to hotel business. Its users share information about quality of hotel services. On Tripadvisor, more than 748.000 hotels are presented and approximately 260 million visits are registered on monthly basis. It is often criticized in the literature that when posting a comment on the portal, no proof that the person who evaluates the service quality was a hotel guest at all is required, which leaves room for doubting review's credibility. This study aim is to evaluate the credibility of Belgrade hotel reviews on Tripadvisor. Reviews credibility was assessed in two ways. The average score of Belgrade hotel quality services was compared on Tripadvisor with the average mark determined by hotel assessment presented on online booking systems, such as Booking.com, Hotels.com, Expedia.com, Venere.com, and Orbitz.com HRS.com, where before leaving a comment, it is required to prove the stay in the hotel with the reservation, or even with a hotel confirmation about the guest's stay. Also, the average Belgrade hotel reviews on Tripadvisor were compared under various formal categories. The results clearly indicate that there is no significant difference between the assessment of hotel service quality on Tripadvisor and each individual online booking system. It was observed, comparatively speaking, that the average rating of hotel service quality on Tripadvisor is on average lower than the specified average in each of the analyzed booking portal. On the other hand, the obtained results indicate that the users' reviews on Tripadvisor are in line with the formal hotel categories and on average, there were no deviations that would indicate that the lower category hotels are rated better than those belonging to the higher categories.
\end{abstract}

Key words:

Tripadvisor, Reservation systems, Credibility, Hotels, Belgrade. 